\title{
EL PRIMER INFORME OFICIAL DE LOS MONUMENTOS DE LA CIUDAD ARRUinAdA de PALENQUE PRESENTAdo POR JosePh ANTONIO Calderón en 1784
}

Víctor Manuel Esponda Jimeno

\section{Introducción}

$\mathrm{P}$ alenque es una de las vetustas ciudades prehispánicas arruinadas que más ha llamado la atención de los estudiosos de la historia antigua de América. Los materiales que se han escrito al respecto son numerosísimos y su temática variada, todo referente a su suntuosidad arquitectónica y a sus estilizadas esculturas y enigmáticas inscripciones jeroglíficas. Si se enlistara el amplio repertorio de fuentes que versan acerca del particular se precisaría de un no limitado espacio, pero se advertiría en tales fuentes que hay redundancia, repetición y, sin duda, plagio; la mayoría de los estudios toman como referencia las pioneras obras del abate Brasseur de Bourbourge, Ricardo Castañeda Paganini, Paul Félix Cabrera, José Alcina Franch, Ignacio Bernal, Juan Galindo, Lord Kingsborough, Marshall H. Saville, Manuel Larráinzar, Guillermo Dupaix, Ramón de Ordóñez y Aguiar, Antonio de Solís, Manuel Ballesteros Gaibrois, Federico Waldeck, entre otros. Dos buenas panorámicas de los estudios efectuados acerca de las primeras exploraciones y viajes

Víctor Manuel Esponda Jimeno, Doctor en Antropología por la ENAH. Cuerpo Académico: Patrimonio Sociocultural del Centro de Estudios Superiores de México y Centro América de la Universidad de Ciencias y Artes de Chiapas. a Palenque las proporcionan Carlos Navarrete, ${ }^{1}$ María de la Cruz Paillés y Rosaba Nieto. ${ }^{2}$

La referencia obligatoria de todo estudioso del descubrimiento de Palenque lo es la obra que se publicó trunca ${ }^{3}$ del canónigo Ramón de Ordóñez y Aguiar, quien fue el entusiasta más vivaz que se apasionó por esta singular ciudad, animando a civiles y autoridades para que en ella se practicaran exploraciones detalladas, pues creía que esa ciudad era, en gran parte, la clave del origen de los pobladores del Nuevo Mundo, los que pretendía eran antiguos ultramarinos, descendientes de aquellos legendarios personajes bíblicos de oriente. Ordóñez llamó a los prístinos moradores y constructores del Palenque "Culebras", y supuso que descendían en orden lineal de Heveo, Cannan, Cham y Noé. Esta perspectiva difusionista no ha sido bien acogida por los modernos estudiosos en razón de su alto grado conjetural; mas para otros la idea de considerar las frecuentes migraciones pretéritas que partieron del viejo mundo sigue siendo un tema estimulante debido a la gran similitud que presentan los grupos asiáticos con los americanos. No pocos se apartan de esta tentadora suposición, empero algunos estudiosos ${ }^{4}$ han llegado a proponer que el origen de las altas culturas americanas es de procedencia asiática, pues sus complejos tecnológicos plasmados en sus monumentales obras arquitectónicas 
y escultóricas, así como sus remotas tradiciones y leyendas, tienen asombrosa semejanza en su percepción filogenética. La historia eclesiástica indiana se apegaba a esa corriente, y el presbítero Ordóñez, como muchos otros, incluso el obispo Francisco Núñez de la Vega, estaban firmemente convencidos de que los habitantes americanos eran los modernos descendientes de las siete tribus perdidas de Israel.

Poco se sabe del cómo y el por qué el presbítero Ordóñez se obsesionó tanto por la antigua ciudad del Palenque, pero menos se sabe cómo escribió su relacionada obra - que deberá ser publicada completa con un estudio crítico biográfico que pondere bien sus alcances y aportación como obra teórico-histórica de ese legendario pueblo-. Sirvan las siguientes líneas para tener una idea general de quien fue el primer mayólogo que encausó sus afanes en las ahora famosas ruinas de Palenque.

Ramón de Ordóñez y Aguiar nació en Ciudad Real de Chiapa el 11 de octubre de 1730, siendo sus padres el capitán don Nicolás de Ordóñez de Cuenca y Villaquirán, y doña Juana María Álvarez de Aguiar y Zeixas; este matrimonio, que tuvo lugar en 28 de mayo de 1727, procreó siete vástagos, incluso el susodicho, cuya educación la inició desde muy temprana edad cuando sólo contaba con siete años; siendo mozuelo de dieciséis vistió hábitos clericales bajo la custodia y patrocinio de su tío, el obispo fray Joseph Cubero Remírez de Arellano, también fue caudalario del ilustrísimo fray Joseph Vital de Moctezuma. Estando ordenado de subdiácono, a los veintidós años hizo oposición al curato de Xiquipilas y en resulta de la aprobación que mereció en los sínodos del concurso le ordenó el señor obispo Vital, prelado de presbítero, dispensándole sin ampliar un año de edad, librándosele al efecto licencias para predicar el Santo Evangelio y confesar generalmente hombres y mujeres, y se le destinó a servir la capellanía del Hospital Real de Ciudad Real que ocupó por tiempo de cinco años, habiéndose encargado también del gobierno económico de dicho Hospital. Posteriormente se le extendieron las licencias para confesar religiosas y mereció de los ilustrísimos prelados que verbalmente le comunicasen no solamente sus facultades ordinarias, sino también las apostólicas delegadas para que las usase sin reservación alguna. En 12 de septiembre de 1773, el ilustrísimo señor obispo fray Juan Manuel García de Bargas y Rivera le libró el título de examinador sinodal de concursos a beneficios curados, confesores, predicadores y otros ministerios. Fue notario de la curia eclesiástica por tiempo de más de diez años. El ilustrísimo señor García de Bargas le comisionó para la secularización de las doctrinas que servían los religiosos que predicaban en la provincia de zoques. Fue promotor fiscal general eclesiástico con título en forma librado por el señor obispo Francisco Polanco en 14 de mayo de 1777. Desempeñó el cargo de vicerrector gobernador del Colegio Tridentino de la aludida ciudad; en 7 de febrero de 1783 se le despachó por el Santo Tribunal en la ciudad de México título de corrector, espulgador y revisor de libros en la provincia de Chiapa; asimismo fue designado maestro de "ceremonias pontificiales", encargo que desempeñó sin congrua alguna ganándose el pan como labriego. En 1798 le nombró el obispo en turno catedrático de Moral en el Colegio Seminario de Ciudad Real. En 1803 fue nombrado canónigo interino de la Catedral de Chiapa. En 2 de noviembre de 1807 se le dio colación de la canonjía de la Santa Iglesia Catedral, durante nueve años fue capellán de coro de dicha catedral, y por espacio de cinco años secretario del muy ilustre y venerable cabildo eclesiástico, oficio que desempeñó ad honorem; también por cinco años fungió como maestro de ceremonias de la referida catedral.

La carrera eclesiástica del padre Ordóñez fue amplia y a la vez tormentosa en determinados momentos; sus méritos y capacidades fueron siempre muy reconocidas por el pueblo y colegas, pero dentro de la estructura religiosa tuvo no pocos inconvenientes y conflictos; en muchos concursos de 
oposición en que participó resultó vetado o relegado no obstante su notable aprovechamiento. Durante prolongado tiempo en que fue relegado se dedicó a las labores de labriego en un molino de su propiedad sito en las inmediaciones del Camino Real que conducía a Zinacantán. Ordóñez fue un hombre ilustrado, políglota, muy inclinado a la historia americana, a sus antigüedades, y quizá un tanto heterodoxo en cuestión religiosa, lo cual le ocasionó grandes desacuerdos con sus superiores - en particular con don Francisco Vicente del Corro- motivo por el cual resultó marginado y evitado, llegando su situación económica a un extremo crítico, pues era el encargado de proveer y cuidar a su familia, cuatro hermanas doncellas y su anciana madre. Esta incómoda condición le precisó acudir a instancias externas recurriendo al arzobispo de México, el Dr. Alonso Núñez de Haro — conocido de su hermano el Dr. Manuel de Ordóñez, mismo que ejerció en la metrópoli-, a quien le solicitó le procurara encargo donde su señoría creyera conveniente pues en la provincia de Chiapa no hallaba acomodo. El señor Núñez de Haro proyectó enviarlo a La Habana o al Soconusco, pero esa oferta le era adversa pues de aceptarla su familia quedaría desamparada. Dada su crítica situación Ordóñez se trasladó a Guatemala donde permaneció unos años relacionándose con los principales intelectuales, y se dice que formó una tertulia que se enfocó al origen y estudio de Palenque. Durante su estancia en aquel país litigó un asunto en contra del Paul o Pablo Félix Cabrera por plagio de su obra - Historia de la creación...- - en la cual salió airoso Ordóñez. En 1803 volvió a Chiapas y su situación fue un tanto mejor pues se le encomendaron cargos relevantes y con el de canónigo murió en 28 de enero de 1825 en Ciudad Real de Chiapa.

La noticia oficial de la existencia de las ruinas del Palenque la dio en $1735^{6}$ el cura de Tumbalá don Antonio de Solís, tío abuelo de Ramón de Ordóñez por línea paterna, hermano de su abuela doña Marina de Solís, esposa de don Pascual Ordóñez. El cura Solís se estableció con su familia en el pueblo de Palenque, siendo él de fino trato a la vez que muy inclinado en las cosas de los indios; los nativos de allí le informaron de una gran ciudad de "piedras" situada a escasas leguas del poblado, y movido por la curiosidad se dio a la tarea de conocerlas lo cual hizo en compañía de sus sobrinos, yendo entre éstos el joven José de la Fuente Coronado, quien le causó profunda impresión y asombro la magnificencia de dichas ruinas. A este muchacho diez años después se le mandó estudiar Gramática a Ciudad Real donde se relacionó con el doncel Ordóñez quien apenas iniciaba sus estudios menores; de José de la Fuente, Ramón refirió:

Este mozo, dotado de un entendimiento claro y de una comprensión nada común, fue quien me dio las primeras noticias de aquella ciudad, haciéndome (según después he comprendido) una cabal descripción de la magnificencia de sus edificios, primor de su arquitectura, fortaleza de su fábrica, y de todo pormenor de figurones y caracteres que la adornan. $^{7}$

Éste es el antecedente más temprano que a Palenque se refiere y, sin duda, fue lo que a Ordóñez le cautivó, pues a partir de esa noticia su interés por dicho lugar no cesó y su entusiasmo por promoverlo se caracterizó como intenso y persuasivo, incluso en 1770 hizo oposición para el curato de Tumbalá con la idea de explorar y estudiar las mencionadas ruinas, pero la fortuna le fue adversa, aun así continuó con sus indagaciones y su promoción para que fueran exploradas a fondo; pretendió no pocas veces visitar al Palenque pero nunca lo logró; por el contrario, consiguió motivar a su hermano José, ${ }^{8}$ al alcalde mayor don Fernando Gómez de Andrade, hijo de un ministro decano de la Audiencia de Quito, y a don Nicolás de Velasco y Unquera, capitán de milicias retirado, para que practicaran un exploración al referido lugar. Se dice 
que se trasladaron en marzo de $1773^{9}$ y con la ayuda de algunos naturales y ladinos del pueblo de Palenque despejaron ciertas áreas y que al ver la suntuosidad y armonía de sus edificaciones exclamó dicho alcalde “(...) que esto del Palenque no es cosa de indios". Acompañó a los mencionados el teniente de alcalde mayor, don Esteban Gutiérrez de la Torre, quien con más entusiasmo y emoción mandó despejar un área más extensa, instruyó también para que se desmontara una bóveda e infinidad de paredes; abrió un agujero y por él mandó se deslizaran algunas personas que los acompañaban, llegando a una sala que medía como 60 varas de largo aunque su ancho era desproporcionado, encontrando en ella una casa con sus mesas o camas de piedra cubiertas por grandes lajas de una sola pieza labradas primorosamente, de una altura aproximada de una vara. Se informa en este documento que don Esteban era un mozo de gran valor y fortaleza increíble, y que nunca había conocido el miedo, pero al estar en dicha sala experimentó una profunda angustia que le llenó de terror y pánico, pues al estar explorando la bóveda dice haber golpeado el piso con un bastón que llevaba y escuchó que sonaba hueco, lo cual le hizo suponer que se derrumbaría el piso y se precipitarían los que en él se encontraban.

De todo esto tuvo conocimiento Ordóñez e incluso se asegura que los expedicionarios levantaron para él un bosquejo rústico de los monumentos descubiertos.

Transcurrió el tiempo y la idea de explorar Palenque directamente crecía más en Ordóñez, sin embargo su suerte y situación no le favorecieron, de todas formas seguía promoviendo el mencionado lugar a la vez que indagando cuanto de ese lugar y de su historia se supiera. Llegó el año 1784, fecha en que se encontraba a finales de dicho año en Guatemala el cura perpetuo de Chamula don José Ordóñez, hermano suyo, quien por su conducto hizo saber que "las primeras noticias que el señor Presidente tuvo de aquellos, hasta aquí no bien celebrados edificios, los comuniqué a su Señoría por medio de mi hermano".
Esta noticia fue determinante, pues a partir de ella se ordenan las primeras exploraciones oficiales en Palenque, siendo la primera la que efectuó a finales de 1784 don Joseph Antonio Calderón, teniente de alcalde mayor del partido de Tumbalá, radicado en el pueblo de Palenque.

Joseph Antonio Calderón Ladrón de Guevara y Coz nació en Santander, hijo de don Fernando Calderón Ladrón de Guevara y de doña Manuela Coz y Cevallos. Casó con doña Ana Gongoria Landeros. En 1750 fue designado teniente de alcalde mayor del Palenque; en 1790 juez del Partido de Palenque y subdelegado de la intendencia y administrador de Rentas Reales, así como capitán de milicias. ${ }^{10}$

\section{El documento}

El documento que se presenta es una copia incompleta del Expediente original del escrito que redactó Calderón en 1784 - el cual da cuenta detallada de la comisión que le encargó el presidente Estachería-; al parecer es una versión abreviada de dicho Expediente que sólo reproduce el "informe" de los monumentos y omite los pormenores de la exploración; de hecho esta versión es sui géneris en su redacción y parece que el copista se tomó ciertas libertades en su traslado, como se puede constatar en la versión que en 1946 (pp. 22-29) publicó Ricardo Castañeda Paganini en su obra Las ruinas de Palenque: su descubrimiento y primeras exploraciones en el siglo XVIII. ${ }^{1 l}$ Esta obra presenta una versión íntegra del Expediente, pero se percibe en ciertas partes de ella una mala transcripción de ciertas palabras, de hecho es una traslación poco técnica y no estrictamente paleográfica.

La versión aquí presentada es una transcripción modernizada que tiene como propósito agilizar su lectura. El publicarla persigue motivar a los estudiosos de la historia de Palenque para que se emprenda un estudio concienzudo y detallado en que se dé a conocer la versión primigenia comparándola con las otras que puedan existir. 
Descripción del terreno, población antigua, nuevamente descubierta, en las inmediaciones del pueblo de Palenque ${ }^{12}$

Joseph Antonio Calderón

[f 174r] Expediente sobre el descubrimiento de una gran ciudad en la provincia de Chiapa distrito de Guatemala.

El presidente de Guatemala tuvo noticia por el provisor de dominicos fray Tomás Luis de Roca, y un cura de la provincia de Chiapa, que en jurisdicción de su provincia a cosa de tres leguas del pueblo de Palenque se descubrieron las ruinas de una gran ciudad; y por lo que esto pudiera contribuir o ilustrar la historia y las antigüedades, con fecha 28 de noviembre de 1784 mandó a don Joseph Antonio Calderón, teniente de alcalde mayor de dicho pueblo que reconociendo prolijamente aquellas ruinas, y tomando cuantas noticias pueda adquirir por los naturales y cualesquiera otros medios, le informase de todo muy pormenor.

En cumplimiento de esta orden (que va copia autorizada) dio Calderón el informe siguiente que he mandado copiar a la letra del original.

Informe de don Joseph Antonio Calderón teniente de alcalde mayor del Palenque; empleo que al escribir esto servía ya 33 años.

El palacio grande viene a tener como cuatro cuadras, tiene diez puertas, un corredor con diversos escudos, una vara de ancho tienen de grueso las paredes, que son todas de piedra. En el [f174v] segundo corredor hay otros seis nichos, y ocho puertas, el primero tiene de ámbito dos varas y media y lo mismo el segundo. Una pieza algo deshecha a modo de bóveda, pendiente del Palacio con seis escudos; otro frontero con sus puertas labradas, otra bóveda al andar del palacio con una puerta grande y un soldado en cada lado con sus turbantes; $y$ adentro tiene grabada en la pared varias figuras de hombre y de mujeres. Otro salón de quince varas de largo y de ancho cuatro. Sigue otra pieza con muchos cuartos y nichos y seis camas de piedra muy aniveladas. Sigue otro corredor con tres camas de piedra y va circulando a una torre que está como en un patiecillo al modo de campanario que tiene como sesenta varas de largo y cinco de ancho de una parte a otra con su caracol formando escalerilla y contorno del campanario de dicha torre muchas arquerías. Tiene también dicho palacio dos como plazuelas o patios y luego dos corredores lo mismo que los primeros, la dicha torre tiene ocho puertas, esto es entradas, tiene seis piezas demolidas y luego sigue un escalón para adentro de tierra, $y$ al comenzar tiene grabados al modo de escudos muy labrados y adentro hay las mismas piezas que arriba, menos la dicha torre, y si hay siete camas de piedra, y uno como oratorio grande con su mesa, muy labrada su entrada, y hay como diez cuartos con [f175r] diversos escudos y dos figuras de hombres con su morrión de plumas a modo de faldellín o nagüeta tienen hasta la rodilla y con géneros de botas rodilleras y zapatos. Arriba hay otros diez cuartos medio demolidos, otro salón con tres nichos y cinco ventanas en forma de cruces. Otros dos corredores demolidos con diez cuartos según parece por los fragmentos. Tiene un río enfrente de palacio que hace medio circulo al palacio dicho, y del otro lado otro que se encuentra con el primero, y en el mismo está un género de bóveda que sirve de cobertor al río como en espacio de dos cuadras puede haber sido alguna fábrica o molino y ahí se encontró una piedra redonda agujerada en forma de cruz de una banda y otra, y otra piedra lisa redonda grande, y cuantas cosas iré relacionando circulaban a este palacio y se halla a la vega de ambos ríos.

Relación de cosas y como palacios que se encuentran en las caserías de piedra anotadas al margen con su número según el número de ellos.

Una casa de bóveda con seis palmos de grueso, con tres ventanas, un saloncito, un cuarto y tres piezas.

ítem. Otra casa algo deteriorada con treinta varas [f175v] de largo, una sala con tres puertas y su corredor. 1.Ítem. Otra semejante a la segunda.

1. Ítem. Un como oratorio o capilla con una puerta y una ventana. 
1.Ítem. Otra inmediata a la dicha capilla con sus dos cuartos, un salón y tres puertas, una figura con su bastón, al modo de collado, con sus botas como con charnatelas y andalias.

1.Ítem. Otra deteriorada y semejante a las antecedentes, conociendo se por sus cimientos y todos son de bóveda y azotea.

Ítem. Siguen otras muy demolidas aún.

7 que se conocen por los cimientos que serán como siete.

1.ítem. Otra arruinada.

1.Ítem. Otra lo ismo arruinada.

1.Ítem. Otra casa grande también arruinada.

1.ítem. Otra casa muy grande arruinada según sus cimientos.

5.Ítem. Cinco casa demolidas grandes.

3.Ítem. Tres también arruinadas.

1.Ítem. Un palacio grande según sus cimientos.

1.Ítem. Otra casa arruinada con una puerta tapiada.

[f176r] 1. Ítem. Un palacio grande arruinado.

8. Ítem. Otras ocho casas arruinadas.

1.Item. Otra muy grande según sus cimientos.

1.ítem. Otro palacio muy grande según sus cimientos.

1.Ítem. Otra casa cuasi entera con tres puertas, una sala y dos cuartos en medio, un escudo grabado en la pared y al pie del escudo un sótano de tres varas hecho de calicanto.

1.Ítem. Una bóveda al modo de cárcel con dos varas y media en cuadra, con su puerta buena.

1. Item. Otra casa con 20 varas de largo, tres puertas, y su sala y corredor.

2.Item. Dos casas arruinadas muy grandes.

2.ĺtem. Dos casas arruinadas visibles por sus cimientos.

1.Item. Una casa de dieciséis varas de alto y treinta de ancho con cuatro puertas, y una figura de mujer que tiene dos varas de alto y como turbante en la cabeza y sus nagüetas hasta la rodilla, su niño abrazado, y se le observa tener medias hasta los muslos, y sus zapatos, las cintas de la nagua con sus florones llegan hasta los tobillos, de mucho atavío se conoce haber sido; en el corredor de la dicha casa está una tarima muy anivelada con catorce palmos de largo y siete de ancho, tres cuartos con muchísimos caracteres o veneras, toda la casa enlosada.

[f176v] 1. Ítem. Otra casa grande arruinada.

1.Ítem. Otra casa grande arruinada.

1.Ítem. Otra casa del modo de capilla con sus dos aposentillos, un saloncito con su corredor con una figura en la puerta de hombre armado de que tiene bandera en la mano, y en su turbante tiene un escudo con dos soldados a los lados con sus lanzas en las manos y sus escudos al modo que forman un águila y una cruz muy perfecta abajo con muchas ramazones y sus flores de lis, los soldados tienen pelo propio.

1.ítem. Un nicho perfecto con sus ventanas y un sótano hecho de mezcla y dos soldados más con sus morriones dentro de una casa.

1.Item. Otra casa arruinada.

1.Ítem. Otra casa maltratada con una bóveda entera, con dos cuartos y sus sótanos con sus soldados a la puerta y sus morriones.

1.Item. Otro soldado en una casa deteriorada.

1.Ítem. Otra casa semejante a la antecedente con su bóveda.

6. Ítem. Seis más arruinadas.

4. Item. Arruinadas visibles por sus cimientos.

6.Ítem. Seis más arruinadas.

10. Ítem. Diez más arruinadas.

3.Ítem. Tres más arruinadas.

3.Ítem. Tres más arruinadas.

[f177r] 15. Ítem. Quince casas más arruinadas con sus cimientos y señales todas que fueron casas grandes.

1.ítem. Una casa más con un sótano bueno y su escala de mezcla.

10. Ítem. Diez más arruinadas.

5.ítem. Cinco palacios grandes con sus puertas $y$ aposentos lo mismo que uno que otro.

5.Ítem. Cinco caserones más arruinados con sus escalas buenas. 
4.Ítem. Cuatro casas más arruinadas y desde sus cimientos se divisan muchos campos y prados de este pueblo.

20.ítem. Veinte casas arruinadas.

20.ítem. Otras veinte demolidas.

3.Ítem. Otras tres casas arruinadas.

10.ítem. Diez palacios como cuarenta varas de largo arruinados aunque en uno había una puerta y un cuarto entero.

1.Item. Una arruinada.

2.Ítem. Dos arruinadas y la una con su cuarto y alacena con muchos nichos.

7.Ítem. Siete más arruinadas.

4.ítem. Unas cuatro más arruinadas.

5. Ítem. Cinco más arruinadas.

16. Ítem. Dieciséis más arruinadas.

Con advertencia que con todas forman calles como se advierte por las veredas.

[f177v] Todo lo cual es cierto como se podrá ver en todo tiempo que para que conste lo firmo en quince de diciembre de mil setecientos ochenta y cuatro. $=$ Joseph Antonio Calderón.

Acompañado de algunos sujetos de este pueblo, indios y ladinos, fui a la ciudad arruinada, tres leguas de aquí, paraje nombrado Las Casas de Piedra. Vi primero ocho casas en ellas, una por su magnitud y estructura Ilamo Palacio. Luego, picando maleza y abriendo veredas, seguí hasta dar a otras muchas casas, o palacios muy suntuosos que el $1^{\circ}$ pasando por muchos cerros, a veces a gatas, hallé tales edificios a todos 4 vientos del principal palacio, en tres días que duró el reconocimiento. Los que van anotados: los más caen al sur do sería la corte; está el sitio intransitable por la espesura del monte y los precipicios. Cuando menos estará abandonada la ciudad 3 o 4 siglos, pues ya muchas casas tienen sobre sí árboles de 3 o cuatro varas de grueso. Las tres leguas de este lugar a la ciudad derruida debieron de ser campos, y aquel rey dominaría todas las tierras que hay en las 90 diez leguas por todos 4 vientos que reconoce por suyas este lugar del Palen- que; en efecto, cavando por todo ese ámbito se hallan cimientos de casas, ollas y ladrillos, y pudo extenderse su dominio a todo Tabasco y los ríos de Usumacinta que todo es una tierra muy fértil, observándose que se si desamparan algunos caseríos con pocos años se hace un monte. Los cerros y precipicios pueden formarse de las ruinas de las casas "sirviendo de encuentro a los basuras, tierra y arena" que las aguas en tan dilatado tiempo acarrearían y abriendo [f178r] brecha para su corriente formarian los dichos precipicios. Nadie hallo que de razón de que esto fue: la obra es suntuosísima aunque tosca y de gran firmeza. Las figuras que inserto están esculpidas con mucho primor en las paredes de los palacios, todas de piedra "muchas hay de extraños vestidos y plumajes y mujeres con sus chicuelos en los brazos agigantados, muchos escudos y ese género de inscripción a más de que están dentro de un palacio grande, y desde allí se divisan los campos y las lagunas de todo este país". Plutarco, según dicen, refiere que los romanos traían las medias lunas en el calzado, confesando con eso la inmortalidad del alma. Serían romanos los que aquí dominaron? 0 españoles venidos de la dominación de los moros hasta este puerto o surgidos de Catazajá? Cartagineses de los que se dice vinieron a América? Nada sé?

[f180v] Visto el anterior informe, el presidente capitán general de Guatemala don Joseph Estachería mandó con fecha 27 de enero de 1785 que don Antonio Bernasconi, arquitecto de las obras reales de la ciudad de Guatemala, hiciese nuevo reconocimiento de la ciudad arruinada con arreglo a una instrucción de 17 capítulos, que le dio fecha de 29 del mismo enero.

\section{Comentario}

Se aprecia que Ordóñez fue sin duda el primero y más entusiasta estudioso del Palenque; sus esfuerzos y afanes lograron que el Presidente de la Audiencia de Guatemala don Joseph de Estachería procurara las primeras expediciones oficiales y financiadas con 
propósitos científicos. El descubrimiento al mundo "civilizado" de las ruinas de Palenque se debe, pues en justicia, a los buenos oficios del presbítero chiapaneco que puso gran parte de sus energías y recursos en el acopio de datos y en difundir la importancia y majestuosidad de aquella vetusta ciudad que creyó debió ser la metrópoli más importante de los antiguos pobladores americanos cuyos ancestros supuso vinieron de las lejanas tierras orientales.

A la modesta expedición de Calderón le siguió la que instruyó al año siguiente el señor Estachería, mandando a dicho lugar al arquitecto Bernasconi quien con precisas instrucciones hizo el registro arquitectónico y plástico de las ruinas, esculturas y estelas de palenque en 1785 .

En 6 de mayo de 1787, el capitán don Antonio del Río, comisionado por la corona española y noticioso de todo lo realizado en dicho lugar, llevó a cabo otra exploración más en forma; en 18 de dicho mes y año comenzó el desmonte con hacha y fuego; estuvo despejando y registrando el sitio durante 38 días que dieron por resultado un interesante informe, del que también tuvo copia Ordóñez por ser uno de los promotores de dicha empresa.

Éstas son las primeras exploraciones que dieron a Palenque fama mundial, advirtiéndose que la primera que corrió a cargo de Calderón fue bastante intensiva debido a que dicho lugar se hallaba muy enmontado no obstante haber practicado sus predecesores sendos desmontes para liberarlo de la exuberante maleza que las cubría y ponerla un tanto al descubierto; asimismo es evidente que Calderón no tenía habilidad alguna en el trazo y dibujo, como se aprecia en sus rústicos diseños que acompañan su informe, no obstante son el antecedente y referente gráfico más temprano del que se tiene conocimiento. Los casi caricaturescos dibujos de Calderón los retomó y redibujó in situ el artista Ricardo Armendáriz en la exploración que estuvo a cargo del capitán del Río; el informe que dicho capitán presentó es el que más se ha difundido, quedando relegado el que redactó Calderón que, dicho sea de paso, es poco conocido y, en Chiapas cuna del Palenque, no se ha difundido desde hace más de dos siglos.

\section{Notas}

${ }^{1}$ Palenque, 1784. El inicio de la aventura arqueológica maya, 2000. Instituto de Investigaciones Filológicas, Instituto de Investigaciones Antropológicas y Centro de Estudios Mayas, Universidad Nacional Autónoma de México (Cuaderno núm. 26).

2 "Primeras expediciones a las ruinas de Palenque: Josef Antonio Calderón y Antonio Bernasconi”, Arqueología 4, 1990, pp. 97-128. Segunda época. Revista de la Dirección de Arqueología del Instituto Nacional de Antropología e Historia. México.

${ }^{3}$ Historia de la creación del cielo y de la tierra, Conforme al sistema de la Gentilidad Americana.Theologia de las Culebras. Figurada en ingeniosos Gerogliphicos, Symbolos, Emblemas y Metaphoras, Diluvio Universal, Dispersión de las Gentes. Verdadero origen de los Indios: su salida de Chaldea; su transmigración á estas partes Septentrionales; su transito por el Oceano, y derrota que siguieron, hasta llegar al Seno Mexicano. Principio de su Imperio, Fundación, y destrucción de su antigua y primera Corte poco há descubierta, y conocida con el nombre de Ciudad de Palenque. Supersticioso culto con que los antiguos Palencanos adoraron al verdadero Dios figurado en aquellos Symbolos ó Emblemas, que colocados en las Aras de sus Templos, últimamente degeneraronen abominables Idolos. Libros, todos de la mas venerable antigüedad < sacados del olvido unos, nuevamente descubiertos otros; e interpretados sus Symbolos, Emblemas y Metaphoras, conforme al genuino sentido del phrasismo americano, escrita en 1789 , y publicada incompleta en 1907 por el Dr. Nicolás León. México.

${ }^{4}$ Vide Manuel Larráinzaren su monumentalobraEstudios sobre la historia de América, sus ruinas y sus antigüedades, comparadas con lo más notable que se conoce del otro continente en los tiempos más remotos, y sobre el origen de sus habitantes. Imprenta de Villanueva, Villageliu y Comp. 
México. Tomos I y II. 1875; Estudios sobre la historia de América, sus ruinas y sus antigüedades, comparadas con lo más notable que se conoce del otro continente en los tiempos más remotos, y sobre el origen de sus habitantes. Imprenta de Villanueva Francesconi é Hijos, México. Tomos III y IV. 1876. Larráinzar conoció la obra de Ordóñez y sin duda ésta la influenció para escribir la suya, incluso se interesó tanto por Palenque que dos de sus hermanos, Ramón y Felipe, se ocuparon de satisfacer sus encargos; el primero, siendo vicegobernador de su estado en 1848 expidió una ley para proteger los monumentos prehispánicos en Chiapas, el segundo llevó a cabo una expedición a Palenque siguiendo las instrucciones de su hermano, siendo una de ellas el mandar aserrar varios robustos caobos y cedros que se encontraban sobre las pirámides para fechar su antigüedad con base en los anillos que presentaran y tener un referente cronológico posterior a la edificación de aquellos majestuosos monumentos (este ingenioso método de fechamiento es lo que años más tarde se le dio el nombre de dendrocronología). Un destacado académico del siglo XX, el Dr. Paul Kirchhoff, se entusiasmó en los últimos años de su productiva existencia por esta hipótesis difusionista (cf. Mexiko und die Alte Welt: Die Mexikanistik ver neuen Perspektiven, "Festschrift für Ad E. Jensen", Teil I: 293-307. Munchen, 1964).

${ }^{5}$ Constitvciones Dioecesanas del Obispado de Chiappa, Hechas, y ordenadas Por Su Señoria Illustriss, el Señor Maestro D. Fr. Francisco Nvñez de la Vega, del Orden de Predicadores, Obispo de Civdad Real de Chiappa, y Soconusco, del Consejo de sv Magestad, Año de MDCXCII. En Roma año de MDCCII. En Nueva imprenta, y Formacion de Caracteres de Caietano Zenobi,
Entallador de Nuestro Señor Papa Clemente XI en la Gran Curia Innocenciana. Con licencia de los Superiores.

${ }^{6}$ En un comunicado que suscribe Ordóñez en 1885 anota que su tío había tomado posesión de dicho curato "hará tiempo de 50 años" (Ms. Biblioteca del Museo Nacional de Antropología e Historia, Fondo Reservado, clasificación E.C.T. 3-226. México. D. F.)

${ }^{7}$ Ms. Biblioteca del Museo Nacional de Antropología e Historia, Fondo Reservado, clasificación E.C.T. 3-226. México. D. F.

${ }^{8}$ Con certeza no se tiene noticia de que José Ordóñez haya ido en la expedición, pero algunas fuentes lo dan por válido y cierto, quien escribe tiene reservas al respecto pues Ramón sólo informa que su hermano se ofrecía a costearle el viaje a ese lugar.

${ }^{9}$ En la sección "Comunicado", se publicó el informe de esta exploración que paraba en poder de fray Thomas Luis de Roca, cuya copia se hallaba en el convento de dominicos de Guatemala, la cual envió desde Comitán don Juan Pablo Anaya al periódico Águila Mexicana, año III, No. 236, del miércoles 7 de noviembre de 1825, pp. 3 у 4.

${ }^{10}$ Para mayores detalles de su servicios públicos véase Paillés y Nieto, op. cit., p. 99, vide nota 3, supra.

${ }^{11}$ Publicaciones del Ministerio de Educación Pública, Tipografía Nacional, Guatemala, Centro América [Incluye los dibujos de Calderón].

${ }_{12}$ Colección Muñoz, signatura A/118 dentro de esta Colección Signatura 9/4853 general de la Academia.Folio 186 al 209. Academia de Historia [copia digitalizada donada al Archivo Histórico Diocesano de San Cristóbal de Las Casas, por el presbítero José Herrera Alcalá]. 


\section{Dibujos del Capitán Joseph Antonio Calderón}
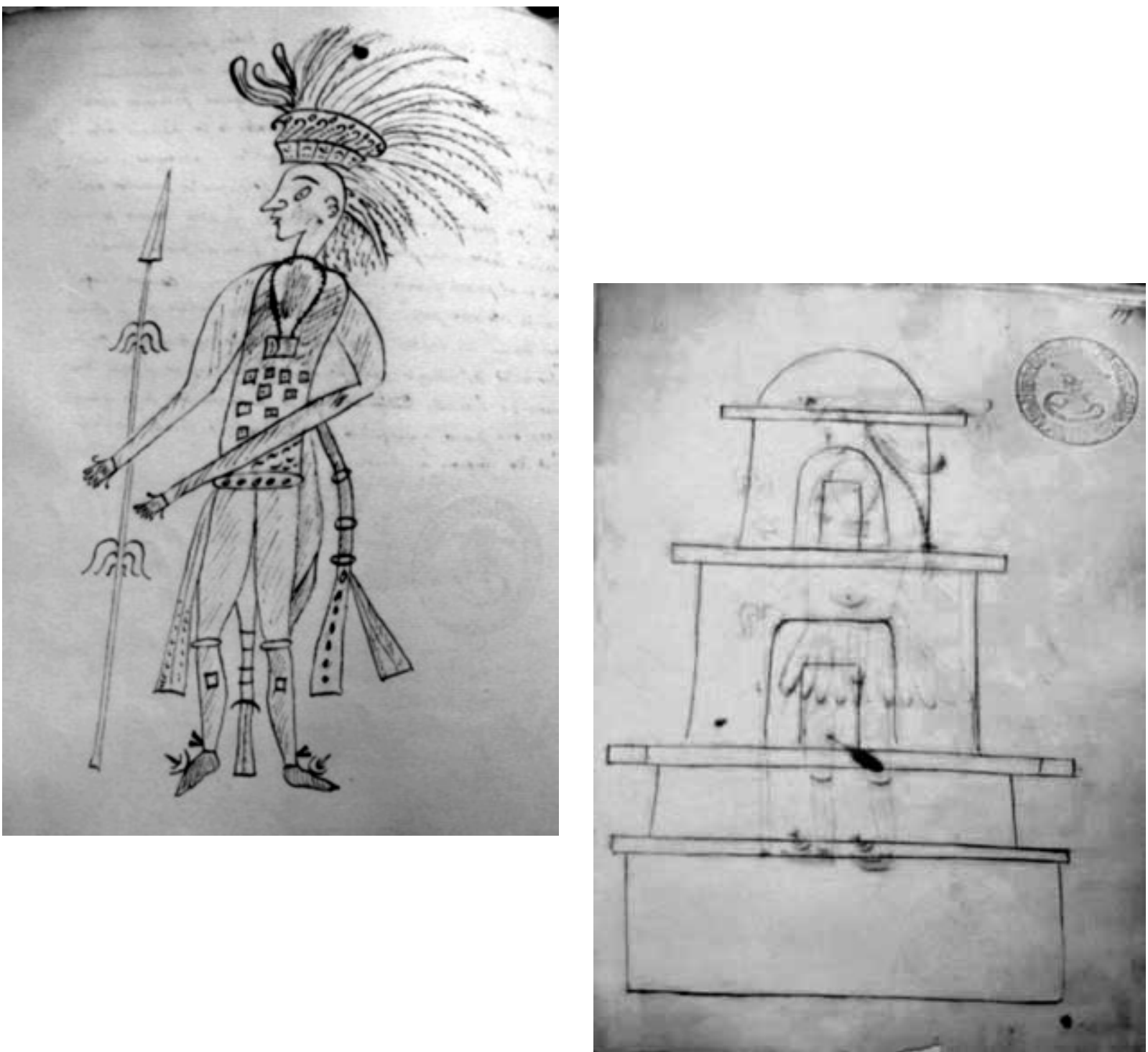

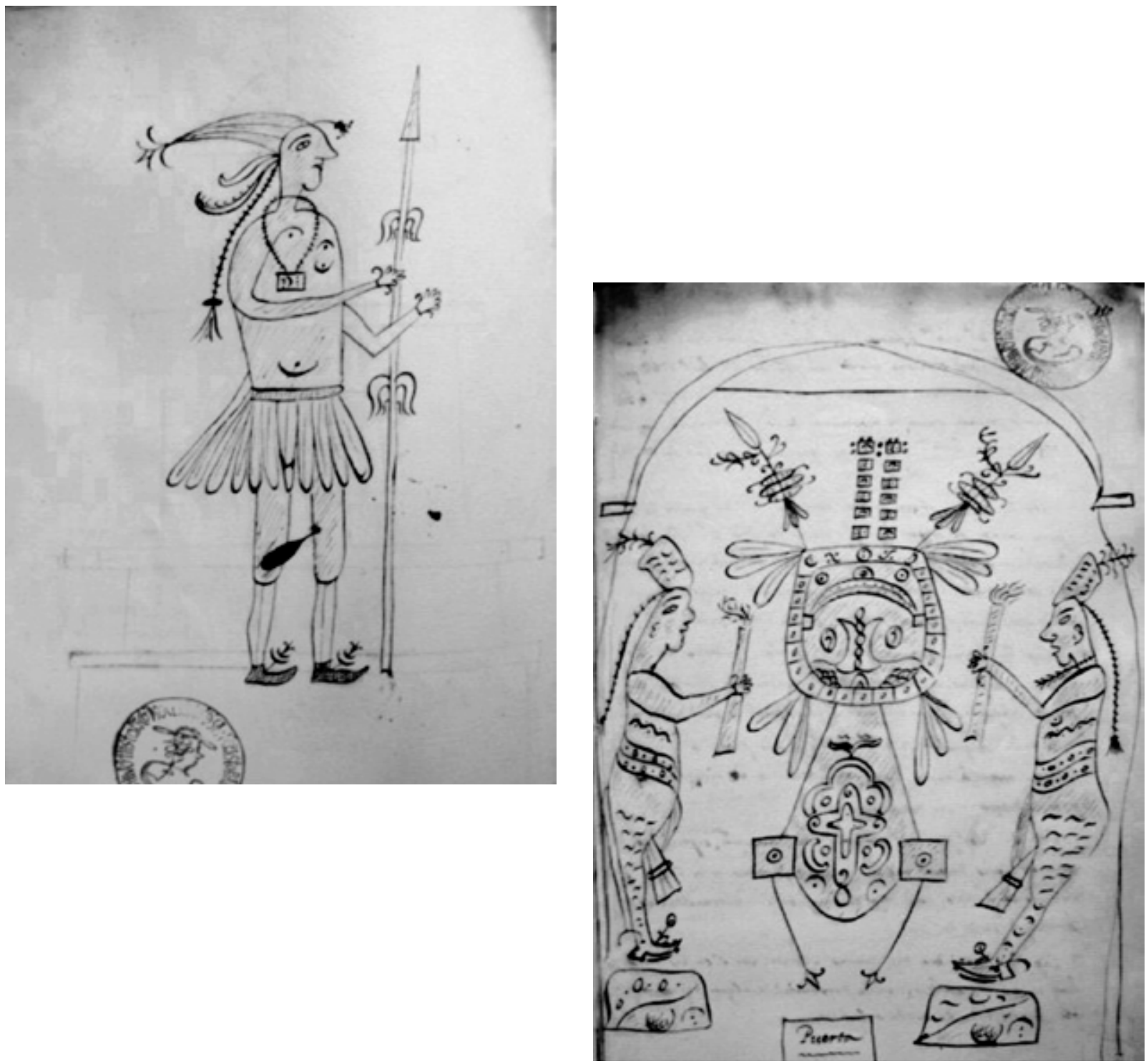


\section{Dibujos del arquitecto de obras reales Antonio Bernasconi}
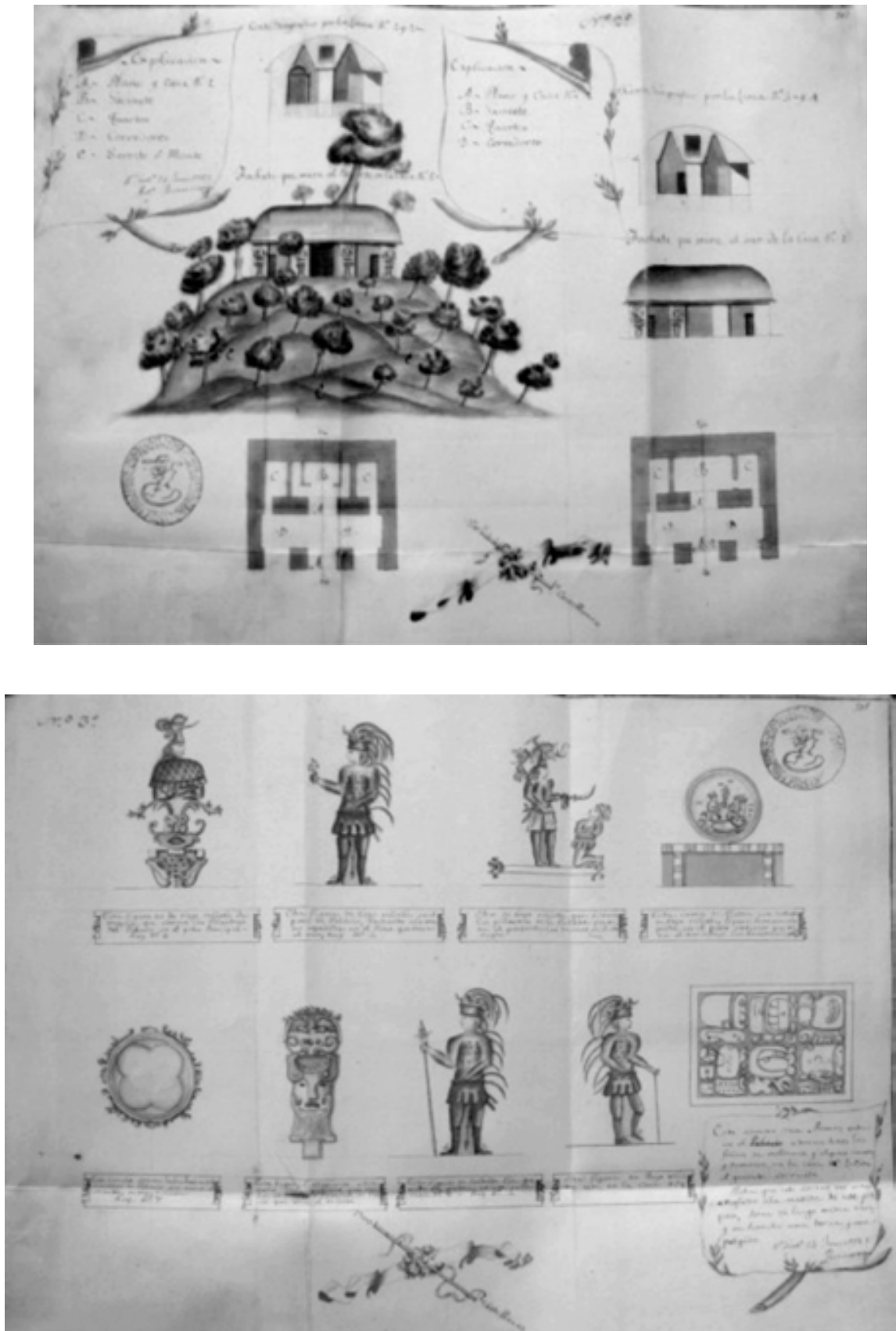


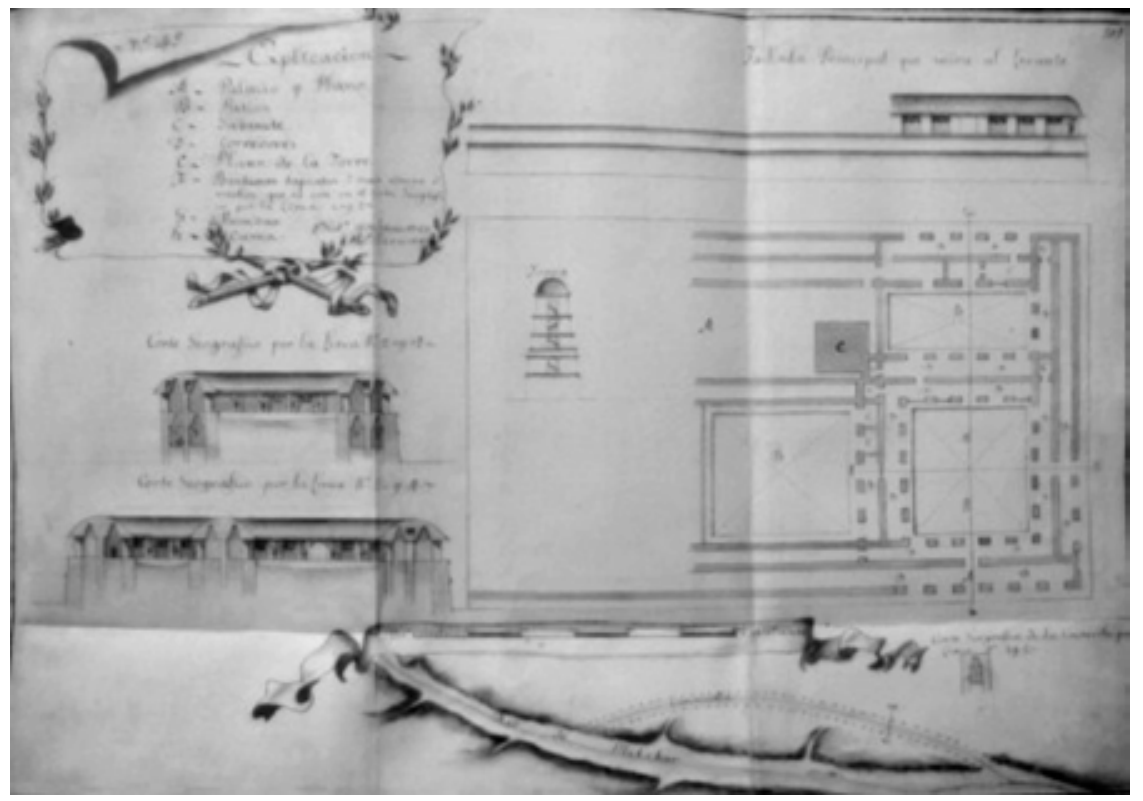

